\title{
DEVELOPMENT OF MODEL FOR SEAT BELT USEAND ASSESSMENT OF PERSPECTIVE BEHAVIOR AMONG INDIAN DRIVERS
}

\author{
Ballem Praveen ${ }^{1}$, Adepu Ramesh ${ }^{2}$, Molugaram Kumar ${ }^{3}$ \\ 1,2 Department of Civil Engineering, VNR VignanaJyothi Institute of Engineering and Technology, \\ Hyderabad, Telangana, India \\ ${ }^{3}$ Department of Civil Engineering, University College of Engineering, Osmania University, Hyderabad, \\ Telangana, India
}

Received 11 May 2019; accepted 14 October 2019

\begin{abstract}
The drivers and passengers of motorbikes and cars are vulnerable on Indian roads as they contribute for larger share of proportion in total crashes. The statistics provided by Ministry of Road Transport and Highway (MoRTH) for the year 2017, the respective crash proportional share for drivers and passengers was observed as 34 and 25 percent. Most of these crashes results in fatality and thus contributes for the increases in severity. One of the major reasons for this severity is not wearing seat by the drivers driving cars. This article aims in understanding the perspective of drivers and prediction models towards wearing of seat belt. A generalized linear model (GLM) and negative binomial model (NBM) was developed to find the risk factors influencing for not wearing seat belt and predicting the probability of wearing seat belt. The results exhibits that the variables such as car type, road type, time of day and day of week are found to be significant in predicting the probability of wearing seat belt. The performance of GLM is better than the NBM for prediction of seat belt wearing. It is observed that the nearly $50 \%$ of drivers and $94.1 \%$ of passengers in rare seat of a car were not wearing seat belts. Seat belt wearing by yellow / taxi plate drivers was found to be $10 \%$ less than that of white plate drivers (private vehicles). The results of this study will be useful for reducing the crash severity rates by implementing appropriate awareness and enforcement programs in and around the metropolitan cities.
\end{abstract}

Keywords: prediction model, driver's perspective, seat belt, risk factors.

\section{Introduction}

India has second largest crash rate among the twenty two developed and developing countries (MORTH, 2017). Passenger car contributes for $24.5 \%$ and is ranked second among the total road crashes. The increase in crash severity is due to not wearing seat belts while driving (Mohammadi, 2011). The statistics summarized by Ministry of Road Transport and Highway (MORTH) shows that $64 \%$ of drivers and $72 \%$ of passengers were met with fatality due to not wearing of seat belt in the year 2017 (MORTH, 2017). In this context this article attempts to identify the factors that are influencing for not wearing seat belt and analyze driver's perspective behavior. The perspective behavior was discussed in terms of attitude and knowledge of drivers which varies based on socio-demographic variables of driver and topographic conditions of road network (Strine et al., 2010). The risk factors associated with not wearing seat belt needs to be analyzed by adopting appropriate statistical techniques. Mostly the traffic

\footnotetext{
${ }^{2}$ Corresponding author: ramesh_a@vnrvjiet.in
} 
administrators adopt awareness programs or enforcement measures for improving the wearing of seat belt among passenger car drivers. In particular with metropolitan cities traffic administrators finds difficult to provide enforcement measures on each route of urban road network for wearing of seat belt by the drivers. Statistical prediction models shall be helpful in classifying the routes based on the use of seat belt. Traffic network routes where enforcement is much difficult, strategic awareness programs will be helpful in reducing the crash severity by increasing the rate of wearing seat belt.

To meet the above requirements following objective was framed: (i) to develop prediction models for wearing of seat belt and to identify the risk factors associated for not wearing seat belt; (ii) to analyze the driver's attitude and knowledge towards wearing of seat belt.

\subsection{Literature Review}

Many studies have explained on the perspective behavior of road users in their respective countries towards road safety, a few limited studies were carried in India for examining road user's perspective towards wearing of seat belt. Aghamolaei et al., (2011) developed a multiple regression for prediction of helmet use and explained that perceived behavior of driver is significant in predicting helmet use. Han \& Xu, (2014) explained several goodness of fit statistics such as MAD, MSPE, MCPD etc., for comparing the predicted data. Drivers prefer to wear a seat belt while driving on highways than minor roads and for long distances than short distances (Huang et al., 2011). The preference of wearing a seat belt use will also varying with the age of driver and passenger (Huang et al., 2011 and $\mathrm{Ma}$ et al., 2012). Jermakian and Weast, (2018) found that the fatality rate is higher among rear passengers as most of them do not wear seat belt, one of the reason is that the rear passenger believe they are much safer than drivers. The effective use of seat belt can decrease the severity of the injury, prevents chest injury by restraining the driver/passenger chest hitting any object in front (Abu-Zidan et al., 2012 and Wang and Jiang, 2003). Ma et al., (2012), Pickrell and Li, (2016), Strine et al., (2010), recommend a strategic awareness programs and strict enforcement to improve the rate of seat belt wearing while driving.

Jermakian and Weast, (2018), Fernandes et al., (2010), Strine et al., (2010) and Tison et al., (2010) collected socio-demographic variables such as gender and age for analyzing the perspective behavior of passenger car drivers. The driver characteristics and perspective data was collected by different approaches, a few to mention like Ma et al., (2012) adopted roadside interview method, Jermakian and Weast, (2018) and Ranney et al., (2010) used web-based and telephone survey process and Abu-Zidan et al., (2012), Huang et al., (2011) and Ma et al., (2012) collected the data through field observational survey methods.

Not much study was performed on passenger car drivers for reducing the crash severity specifically for mixed traffic condition like India.

\section{Methodology}

A Roadside observational survey, driver's perspective survey, and modeling techniques are adopted for this study. The sequence of methods adopted was detailed in these steps below: 
- A detailed literature survey was carried;

- Survey sheets and a questionnaire for driver's perspective were prepared;

- Roadside observational survey was carried;

- Driver's perspective survey was carried through roadside interview and online response sheet;

- GLM and NBM were developed and a chi-square test was carried;

- Goodness of fit statistics was calculated to evaluate the model performance.

\subsection{Roadside Observational Survey}

Roadside observational survey was performed on three arterial and three sub-arterial roads of Hyderabad city. Observations were recorded for three times in a day i.e., morning (8:00 am to 10:00 am), afternoon (12:00 pm to $2: 00 \mathrm{pm})$ and late afternoon $(4: 30 \mathrm{pm}$ to $6: 30 \mathrm{pm})$ on weekdays and also at the same time on weekends i.e., on Saturday and Sunday. The four-wheelers which were passing through the selected point of the road observed for the variables included seat belt use (by driver and passengers), gender, predicted age group $(<25,26-35,36-50$ and $>50$ years), car type (white plate-cars used for personal use, these cars travels for less duration in a day and yellow / taxi plate- cars are used for public as cabs, these travels for longer duration in a day by the same driver), road type, time of day and day of week.

\subsection{Drivers Perspective Survey}

A questionnaire was developed with the predominant questions adopted from literature (Jermakian and Weast, 2018 and Huang et al., 2011) and most of these questions are in the form of multiple choice for fast answering. Survey was carried through two approaches; one roadside interview and another online response sheet. Road side interview was carried at observational survey locations. The drivers, who parked their vehicle at supermarkets, service centers, and restaurants etc., were asked opportunistically to answer the questionnaire. Another side an online response sheet link (https://goo.gl/forms/ xH6Ke7ImCOZ23y0R2) was circulated through social networks and requested to fill the response sheet. The questionnaire included attitude and knowledge related questions along with socio-demographic questions as gender and age group (as shown in table 4). A total of 956 samples were collected among which male responders are 818 , female responders are 138 and age group category of $<26$ years are 548, 26-35 years were 236, 36-50 years were 93 and age group $>50$ years were 79 responders.

\subsection{Modeling Techniques}

Negative binomial technique with binomial distribution and generalized linear model with normal distribution were used for the development of prediction models.

\subsubsection{Negative Binomial Model (NBM)}

Negative binomial or Poisson-gamma technique is used for development of seat belt wearing prediction model. This model is developed considering depended variables as seat belt use (if wearing- 0 and if not wearing- 1 ) and independent variables as gender, age group, car type, road type, time of day and day of week (coding summarized in table 1). The probabilistic structure of negative binomial regression model for this study is as follows.

The mean of Poisson distribution is structured as: 
$\mu_{i t}=f\left(x_{i} ; \beta_{i}\right) \operatorname{EXP}\left(e_{i t}\right)$

This is extended as:

$\mu_{i j}=\operatorname{EXP}\left(\beta_{0}+\beta_{1}\left(X_{1}\right)+\beta_{2}\left(X_{2}\right)+\beta_{3}\left(X_{3}\right)+\right.$

$\left.\left.\beta_{4}\left(X_{4}\right)\right)+\beta_{5}\left(X_{5}\right)+\beta_{6}\left(X_{6}\right)\right)$

Where,

$\mu_{i j}$ is the mean of seat belt wearing probability;

$\beta_{0}$ is the Constant;

$\beta_{\mathrm{k}}$ isCo-efficient (estimated) of variable $k$; $\mathrm{X}_{\mathrm{k}}$ is the value of independent variable.

\subsubsection{Generalized Linear Model (GLM)}

A generalized linear model with normal distribution of response variable is used for development of seat belt wearing prediction model. The structure of GLM used for this study is similar to multiple linear regression as shown in equation 3 .

$\left.\mu_{i j}=\beta_{0}+\beta_{1}\left(X_{1}\right)+\beta_{2}\left(X_{2}\right)+\beta_{3}\left(X_{3}\right)+\beta_{4}\left(X_{4}\right)\right)+$ $\beta_{5}\left(X_{5}\right)+\beta_{6}\left(X_{6}\right)$

Where, the dependent and independent variables are same as explained in section 2.3.1.

\subsection{Perspective Data Analysis}

A descriptive analysis and chi-square test were performed to identify the relationship between socio-demographic (Gender and Age) variables and attitude, knowledge of drivers towards wearing of seat belt while driving.

\subsection{Goodness-of-Fit Statistics (GOF'S)}

The performance of GLM and NBM models for predicting the rate of seat belt wearing were evaluated by calculating the GOF's using three approaches.

\subsubsection{Mean Absolute Deviance (MAD)}

The MAD is the normal of the absolute deviation of predicted data from observed data (Oh et al., 2003) andis calculated using the equation 4 .

$\mathrm{MAD}=\frac{1}{n} \sum_{i=1}^{n}\left|\hat{y_{i}}-y_{i}\right|$

Where, $\mathrm{n}$ is number of observations, $\hat{y_{i}}$ is predicted and $y_{i}$ is observed rate of seat belt wearing.

\subsubsection{Mean Squared Predictive Error (MSPE)}

The MSPE is the normal of the squared deviation of predicted data from observed data. In general MSPE is used to assess the error associated with the validation data set (Geedipally et al., 2010 and Oh et al., 2003) and is calculated using the equation 5 .

$\operatorname{MSPE}=\frac{1}{n} \sum_{i=1}^{n}\left(y_{i}^{\wedge}-y_{i}\right)^{2}$

\subsubsection{Maximum Cumulative Residual Plot Deviation (MCPD)}

The MCPD is the absolute maximum value that is deviated from the center point (from 0 ) of the cumulative residual plot. The cumulative of the difference between predicted and observed data is the cumulative residual. If the cumulative residual values fall as closer to center or zero the better is the model performance (Jonsson et al., 2009).

\section{Data Analysis Results}

In this section results for roadside observations, GLM, NBM Model parameters, GOF statistics and driver's perspective analysis results are discussed. 


\subsection{Roadside Observations}

Table 1 and 2 provides the results of roadside observations. Overall 3345 drivers and 2643 passengers were observed at all study locations. The drivers who were not wearing seat belt was observed to be more in male gender $(49.8 \%)$ than female gender (36.4\%). It was found that white plate drivers were nearly $10 \%$ more than yellow plate drivers for not wearing a seat belt. The rate of wearing a seat belt on minor roads $(39.3 \%)$, at afternoons $(47.2 \%)$ and weekends (49.7\%) observed to be low. Nearly $50 \%$ of drivers were not wearing a seat belt in all aspects.

Table 1

Characteristics of Seat Belt Wearing Among Four Wheeler Drivers in Hyderabad

\begin{tabular}{|c|c|c|c|}
\hline & \multicolumn{2}{|c|}{ Seat Belt Wearing } & \multirow{2}{*}{ Total } \\
\hline & Not Wearing & Wearing & \\
\hline $\begin{array}{l}\text { Driver Characteristics } \\
\text { (Coding for analysis) }\end{array}$ & $48.6 \%$ & $51.4 \%$ & 3345 \\
\hline \multicolumn{4}{|l|}{ Gender } \\
\hline Male $(0)$ & $49.8 \%$ & $50.2 \%$ & $3121(93.3 \%)$ \\
\hline Female (1) & $36.4 \%$ & $63.6 \%$ & $224(6.7 \%)$ \\
\hline \multicolumn{4}{|l|}{ Age group } \\
\hline$<26$ years $(0)$ & $43.6 \%$ & $56.4 \%$ & $171(5.1 \%)$ \\
\hline $26-35(1)$ & $51.2 \%$ & $48.8 \%$ & $1187(35.5 \%)$ \\
\hline $36-50(2)$ & $48.7 \%$ & $51.3 \%$ & $1371(41 \%)$ \\
\hline$>50$ years $(3)$ & $50.9 \%$ & $49.1 \%$ & $616(18.4 \%)$ \\
\hline \multicolumn{4}{|l|}{ Type of Car } \\
\hline White Plate $(0)$ & $47.3 \%$ & $52.7 \%$ & $2512(75.1 \%)$ \\
\hline Yellow Plate (1) & $58.1 \%$ & $41.9 \%$ & $833(24.9 \%)$ \\
\hline \multicolumn{4}{|l|}{ Road type } \\
\hline Major road $(0)$ & $48.0 \%$ & $52.0 \%$ & $2275(68 \%)$ \\
\hline Minor road (1) & $60.7 \%$ & $39.3 \%$ & $1070(32 \%)$ \\
\hline \multicolumn{4}{|l|}{ Time of day } \\
\hline Morning (0) & $45.0 \%$ & $55.0 \%$ & $706(32.4 \%)$ \\
\hline Afternoon (1) & $52.8 \%$ & $47.2 \%$ & $906(37.6 \%)$ \\
\hline Evening (2) & $51.5 \%$ & $48.5 \%$ & $1004(30 \%)$ \\
\hline \multicolumn{4}{|l|}{ Day of week } \\
\hline Weekday (0) & $44.6 \%$ & $55.4 \%$ & $2051(61.3 \%)$ \\
\hline Weekend (1) & $50.3 \%$ & $49.7 \%$ & $1295(38.7 \%)$ \\
\hline
\end{tabular}

A few percentage (5.9\%) of passengers were observed wearing seat belt, most of them were front passengers. The rate of wearing seat belt among passengers was observed to be low in females
(5.6\%), on minor roads $(5.4 \%)$, during evenings (4.2\%) and on weekends (2.3\%). Passengers with white plate cars were $3.5 \%$ more in wearing a seat belt than on yellow/ taxi plate cars. 
Table 2

Characteristics of Seat Belt Wearing Among Four Wheeler Passengers in Hyderabad

\begin{tabular}{|c|c|c|c|}
\hline & \multicolumn{2}{|c|}{ Seat Belt Wearing } & \multirow[b]{2}{*}{ Total } \\
\hline & Not Wearing & Wearing & \\
\hline Passengers Characteristics & $94.1 \%$ & $5.9 \%$ & 2643 \\
\hline \multicolumn{4}{|l|}{ Gender } \\
\hline Male & $93.8 \%$ & $6.2 \%$ & $1499(56.7 \%)$ \\
\hline Female & $94.4 \%$ & $5.6 \%$ & $1144(43.3 \%)$ \\
\hline \multicolumn{4}{|l|}{ Age group } \\
\hline$<26$ years & $96.7 \%$ & $3.3 \%$ & $304(11.5 \%)$ \\
\hline $26-35$ & $94.7 \%$ & $5.3 \%$ & $642(24.3 \%)$ \\
\hline $36-50$ & $93.2 \%$ & $6.8 \%$ & $796(30.1 \%)$ \\
\hline$>50$ years & $93.7 \%$ & $6.3 \%$ & $901(34.1 \%)$ \\
\hline \multicolumn{4}{|l|}{ Type of Car } \\
\hline White Plate & $93.2 \%$ & $6.8 \%$ & $1882(71.2 \%)$ \\
\hline Yellow Plate & $96.9 \%$ & $3.1 \%$ & $761(28.8 \%)$ \\
\hline \multicolumn{4}{|l|}{ Road type } \\
\hline Major road & $92.0 \%$ & $8.0 \%$ & $2072(78.4 \%)$ \\
\hline Minor road & $94.6 \%$ & $5.4 \%$ & $571(21.6 \%)$ \\
\hline \multicolumn{4}{|l|}{ Time of day } \\
\hline Morning & $93.3 \%$ & $6.7 \%$ & $796(30.1 \%)$ \\
\hline Afternoon & $93.5 \%$ & $6.5 \%$ & $885(33.5 \%)$ \\
\hline Evening & $95.8 \%$ & $4.2 \%$ & $962(36.4 \%)$ \\
\hline \multicolumn{4}{|l|}{ Day of week } \\
\hline Weekday & $93.7 \%$ & $6.3 \%$ & $1974(74.7 \%)$ \\
\hline weekend & $97.7 \%$ & $2.3 \%$ & $669(25.3 \%)$ \\
\hline
\end{tabular}

\subsection{Generalized Linear Model (GLM)}

The parameters estimate of GLM was shown in Table 3 . The results exhibits that the variables car type, road type, time of day and day of week are significant in predicting the probability of seat belt wearing, whereas the variables as gender and age are insignificant.

The variables as road type and car type have greater impact in predicting the probability of seat belt wearing.

\subsection{Negative Binomial Model (NBM)}

Table 3 also shows the results of negative binomial model for predicting the probability of seat belt wearing. The results exhibits that the variables as car type, road type, time of day and day of week are significant in predicting the probability of wearing seat belt, whereas variables as gender and age are insignificant. The variable as car type and road type are highly influences the probability of wearing seat belt. The standard error of NBM was found to be quite higher than GLM. 
Table 3

Generalized Linear Model (GLM) and Negative Binomial Model (NBM) Estimates

\begin{tabular}{|c|l|c|c|c|c|c|}
\hline \multirow{3}{*}{ Model } & \multirow{2}{*}{ Parameters } & \multirow{2}{*}{ Estimates } & \multirow{2}{*}{ Std. error } & \multirow{2}{*}{ Sig. } & \multicolumn{2}{|c|}{ 95\% Confidence Interval } \\
\cline { 5 - 7 } & & & & & Lower & Upper \\
\hline \multirow{5}{*}{ GLM } & (Intercept) & 0.386 & 0.0260 & 0.000 & 0.335 & 0.437 \\
\cline { 2 - 7 } & Gender & -0.099 & 0.0524 & $0.060^{*}$ & -0.201 & 0.004 \\
\cline { 2 - 7 } & Age & 0.018 & 0.0108 & $0.094^{*}$ & -0.003 & 0.039 \\
\cline { 2 - 7 } & Car type & 0.110 & 0.0207 & 0.000 & 0.070 & 0.151 \\
\cline { 2 - 7 } & Road type & 0.157 & 0.0246 & 0.000 & 0.109 & 0.205 \\
\cline { 2 - 7 } & Time of day & 0.040 & 0.0115 & 0.000 & 0.018 & 0.062 \\
\cline { 2 - 7 } & Day of week & -0.085 & 0.0377 & 0.024 & -0.159 & -0.011 \\
\hline \multirow{3}{*}{ NBM } & Intercept) & -0.925 & 0.0765 & 0.000 & -1.075 & -0.776 \\
\cline { 2 - 7 } & Gender & -0.248 & 0.1770 & $0.162^{*}$ & -0.595 & 0.099 \\
\cline { 2 - 7 } & Age & 0.037 & 0.0314 & $0.240^{*}$ & -0.025 & 0.098 \\
\cline { 2 - 7 } & Car type & 0.209 & 0.0567 & 0.000 & 0.098 & 0.320 \\
\cline { 2 - 7 } & Road type & 0.290 & 0.0650 & 0.000 & 0.163 & 0.418 \\
\cline { 2 - 7 } & Time of day & 0.079 & 0.0328 & 0.016 & 0.015 & 0.143 \\
\cline { 2 - 7 } & Day of week & -0.168 & 0.1137 & 0.040 & -0.391 & 0.055 \\
\hline
\end{tabular}

*insignificant at 0.05 level of confidence

\subsection{Goodness-of-Fit Statistics (GOF's)}

The results of GOF statistics is shown in table 4 for both the models. The GOF statistics indicated that the value nearer to zero has the better model fit (Geedipally et al., 2012 and $\mathrm{Oh}$ et al., 2003). The result shows that the generalized linear model (GLM) has better fit than the negative binomial model (NBM).

Table 4

Results of Goodness-of-fit Statistics for GLM and NBM

\begin{tabular}{|c|c|c|}
\hline GOF methods & GLM & NBM \\
\hline MAD & $\mathbf{0 . 1 0 3 5}$ & 0.1041 \\
\hline MSPE & $\mathbf{0 . 0 1 9 1}$ & 0.0197 \\
\hline MCPD & $\mathbf{2 . 2 8 9}$ & 2.915 \\
\hline
\end{tabular}

\subsection{Seat Belt Prediction Model}

The probability of wearing seat belt was calculated using GLM and NBM models and their deviation from observed probabilities were plotted (shown in Fig. 1). Probabilities were calculated in number of trials with different combinations of independent variables. 


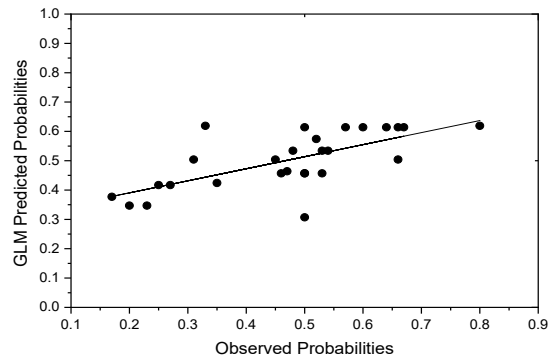

Fig.1.

Probabilities of Seat Belt Wearing from GLM and NBM Models

In $1^{\text {st }}$ trial, car type-white plate, road typemajor road, time of day-morning, day of week-weekday were used and in $2^{\text {nd }}$ trial, car type was changed to yellow/taxi plate and in another trail, road type was changed to minor road. Different combinations are framed to calculate the probabilities of seat belt wearing (gender and age were not used as these variables were insignificant in prediction of seat belt wearing).

Fig. 1 depicts that GLM has less error compared to NBM. The combination of evenings on weekends shows larger error around 0.2 and minor road with yellow/ taxi plate cars shows error around 0.15. An average error of 0.103 was found in GLM predicted values and 0.104 was found in

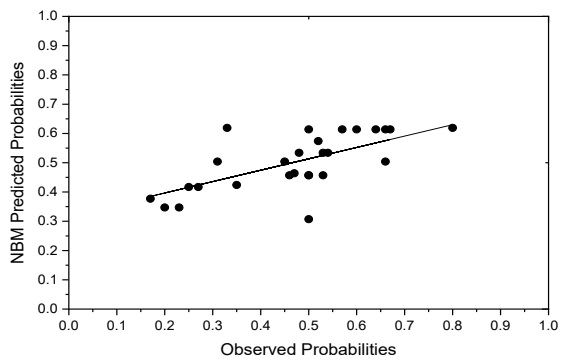

NBM predicted values, which shows that the performance of both the models was quite similar with GLM performing slightly better than NBM.

\subsection{Drivers Perspective Survey}

Overall, 956 drivers were interviewed towards wearing of a seat belt (shown in table $5)$, male $(85.6 \%)$ respondents were more than females (14.4\%). The female drivers (42\%) were more uncomfortable for seat belt wearing than male drivers (37.7\%). Around $50 \%$ of male and $40 \%$ of female drivers were reported that they do not prefer to wear a seat belt for shorter trips and this factor is significantly affected by the age category. Almost $95 \%$ of the respondents agreed that wearing a seat belt is necessary at all times and it is significantly affected by gender and age category also. 


\section{Table 5}

Attitude and Knowledge of Driver Towards Wearing of Seat Belt

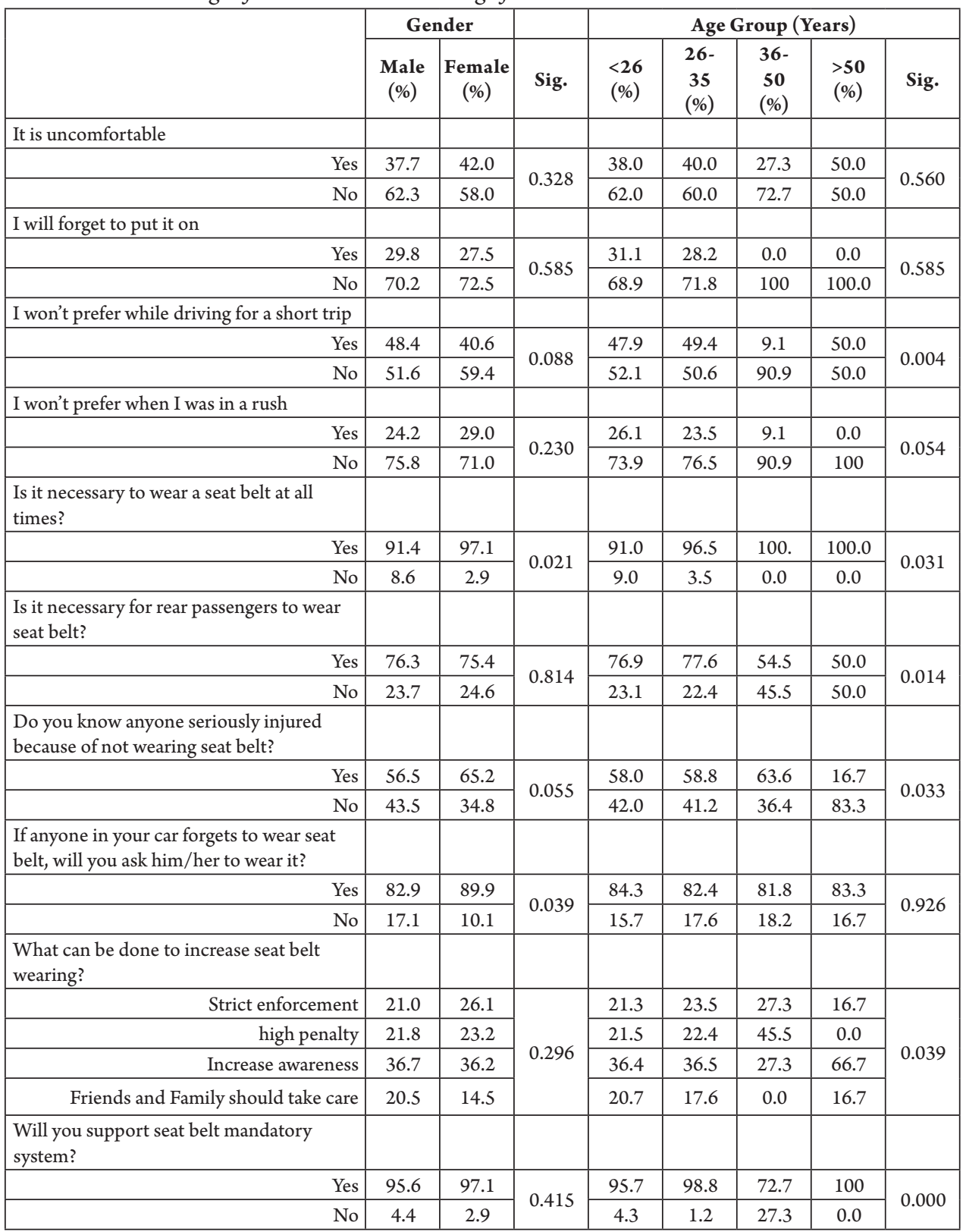


Nearly $75 \%$ of drivers said that wearing of a seat belt is necessary even for rear passengers and about $85 \%$ said that they will ask if someone in their car forget to put a seat belt on. Almost $95 \%$ of respondents supported for seat belt mandatory systems in the car and this support is significantly affected by age category. When we asked to suggest some initiative to increase the rate of seat belt wearing, most of them suggested to increase awareness (36\%) and to provide strict enforcement (25\%).

\section{Summary, Conclusions and Limitations}

\subsection{Summary}

The rate of fatal crashes has been increasing on Indian roads; specifically observed on two-wheeler and four-wheeler vehicles (MORTH, 2017). One among the safety measure is to reduce crash severity rate through using safety tools and being alert while driving. The use of a seat belt in fourwheelers while driving will reduce the crash severity at higher extent (Abu-Zidan et al., 2012 and Wang and Jiang, 2003). From this article we have developed prediction models for seat belt wearing and analyzed the driver's perspective on wearing of seat belt while driving.

It was found that nearly 50\% of drivers were not wearing a seat belt in all aspects which shows the risk of drivers travels in Hyderabad city. The rate of seat belt wearing was found to be low on weekdays, at afternoons and on minor roads. The white plate drivers (52.7\%) were found to be more in wearing seat belt than the yellow plate drivers (41.9\%), this would be due to the more number of trips in a day made by the yellow plate drivers, may makes them to feel uncomfortable to wear seat belt at all the trips.
The generalized linear model (GLM) was found to be better performed than the negative binomial model in predicting the probability of seat belt wearing. The variables as car type, road type, time of day and day of week are found to be highly significant in predicting seat belt wearing. Based on the GOF statistics and error graphs, GLM was said to have better model fit than the NBM.

Though $95 \%$ of the respondents said that wearing of seat belt is necessary at all times, only $50 \%$ were found wearing seat belt and nearly $75 \%$ said that seat belt wearing is necessary even for rear passengers, but only $5.9 \%$ of passengers were found wearing seat belt, in which most of them were front passengers. The reason behind this attitude would be that most of the passengers, especially the rear passengers thinks that they were much safer at back seats (Jermakian and Weast, 2018). Around $40 \%$ of drivers reported that seat belts are uncomfortable to wear and this complaint was more with female drivers than the male drivers. Most of the drivers suggested increasing awareness (36\%), followed by strict enforcement (20\%) to increase the rate of seat belt wearing and $95 \%$ of respondents supported for seat belt mandatory systems in every four-wheeler vehicle which may also increase the rate of seat belt wearing together with awareness programs and enforcement.

\subsection{Conclusions}

The developed models can be used by the traffic administrators in predicting the probability of seat belt wearing on roads of metropolitan cities like Hyderabad for having quick idea of seat belt wearing on a particular route. However, the model results can be differ if the perception of driver towards wearing of seat belt changes. The 
higher risk was observed on minor roads at afternoons for seat belt use. Therefore it is suggested provide strict enforcement even on minor roads, at afternoons and evenings and also for passengers. It is well known that providing enforcement alone cannot increase the rate of seat belt wearing, moreover identifying the driver who was not wearing a seat belt while driving is difficult for the traffic police in metropolitan cities like Hyderabad. Most of the driver's perspectives were significantly affected by age category therefore implementing awareness programs based on age group will be more effective. Thus effective awareness programs and seat belt mandatory systems are implemented together with police enforcement can increase the rate of seat belt wearing.

It is suggested to analyze the changes in the perspective of drivers towards seat belt with the implementation of control measures (awareness programs, enforcement, etc.) for future research and there is research scope for predicting the seat belt use by statistically analyzing the yearly trends in driver's perspective.

\subsection{Limitations}

This article mainly focused on wearing of seat belt while driving in Hyderabad metropolitan city, India. Few variables are considered for model development. The socio-demographic variables such as job type, marital status, income etc., other than gender and age are not considered for this study for driver's perspective analysis. The models may predict different probabilities if the attitude and knowledge of driver towards seat belt changes.

The seat belt use prediction and drivers perspective were analyzed for the current scenario of Hyderabad city, India during the year 2019. This article does not exhibit the scope of understanding the changes in driver's perspective against the past years.

\section{Acknowledgment}

Authors gratefully acknowledge the support provided for collecting roadside observations by the Hyderabad-Cyberabad Police Department and Civil Engineering Department of VNR Vignana Jyothi Institute of Engineering and Technology for providing guidance and support during this study.

\section{References}

Abu-Zidan, F. M.; Abbas, A. K.; Hefny, A. F.; Eid, H. O.; Grivna, M. 2012. Effects of seat belt usage on injury pattern and outcome of vehicle occupants after road traffic collisions: prospective study, World Journal of Surgery 36(2): 255-259.

Aghamolaei, T.; Tavafian, S. S.; Madani, A. 2011. Prediction of helmet use among Iranian motorcycle drivers: an application of the health belief model and the theory of planned behavior, Traffic Injury Prevention 12(3): 239-243.

Fernandes, R.; Hatfield, J.; Job, R. S. 2010. A systematic investigation of the differential predictors for speeding, drink-driving, driving while fatigued, and not wearing a seat belt, among young drivers, Transportation Research Part F: Traffic Psychology and Behaviour 13(3): 179-196.

Geedipally, S. R.; Lord, D.; Dhavala, S. S. 2012. The negative binomial-Lindley generalized linear model: Characteristics and application using crash data, Accident Analysis \& Prevention 45: 258-265.

Geedipally, S.; Patil, S.; Lord, D. 2010. Examination of methods to estimate crash counts by collision type, Transportation Research Record: Journal of the Transportation Research Board 2165: 12-20. 
Han, B.; Xu, J. 2014. Analysis of crash counts using a multilevel zero-inflated negative binomial model, Trans Tech Publ. 912: 1164-1168.

Huang, Y.-H.; Zhang, W.; Murphy, L.; Shi, G.; Lin, Y. 2011. Attitudes and behavior of Chinese drivers regarding seatbelt use, Accident Analysis \& Prevention 43(3): 889-897.

Jermakian, J. S.; Weast, R. A. 2018. Passenger use of and attitudes toward rear seat belts, Journal of Safety Research 64: 113-119.

Jonsson, T.; Lyon, C.; Ivan, J.; Washington, S.; Van Schalkwyk, I.; Lord, D. 2009. Investigating differences in the performance of safety performance functions estimated for total crash count and for crash count by crash type, Transportation research record 2102(1): 115-123.

Ma, S.; Tran, N.; Klyavin, V. E.; Zambon, F.; Hatcher, K. W.; Hyder, A. A. 2012. Seat belt and child seat use in Lipetskaya Oblast, Russia: frequencies, attitudes, and perceptions, Traffic Injury Prevention 13(sup1): 76-81.

Mohammadi, G. 2011. Prevalence of seat belt and mobile phone use and road accident injuries amongst college students in Kerman, Iran, Chinese Journal of Traumatology (English Edition) 14(3): 165-169.

MORTH. 2017. Road Accidents In India-2017. Ministry of Road Transport and Highways. India. Transport Research Wing. 19-22 p.
Oh, J.; Lyon, C.; Washington, S.; Persaud, B; Bared, J. 2003. Validation of FHWA crash models for rural intersections: Lessons learned, Transportation Research Record 1840(1): 41-49.

Pickrell, T. M.; Li, H. R. 2016. Seat belt use in 2015 - Overall results. National Highway Traffic Safety Administration. U.S. Department of Transportation, Traffic Safety Facts Research Note.

Ranney, M. L.; Mello, M. J.; Baird, J. B.; Chai, P. R.; Clark, M. A. 2010. Correlates of motorcycle helmet use among recent graduates of a motorcycle training course, Accident Analysis \& Prevention 42(6): 2057-2062.

Strine, T. W.; Beck, L. F.; Bolen, J.; Okoro, C.; Dhingra, S.; Balluz, L. 2010. Geographic and sociodemographic variation in self-reported seat belt use in the United States, Accident Analysis \& Prevention 42 (4): 1066-1071.

Tison, J.; Williams, A. F.; Chaudhary, N. K.; Preusser Research Group. 2010. Daytime and nighttime seat belt use by fatally injured passenger vehicle occupants. United States. National Highway Traffic Safety Administration.

Wang, Z.; Jiang, J. 2003. An overview of research advances in road traffic trauma in China, Traffic Injury Prevention 4(1): 9-16. doi: 10.1080/15389580309860. 